\title{
A IMPORTÂNCIA DOS GERENTES NA ORIENTAÇÃO EMPREENDEDORA
}

\author{
Marcos Hashimoto - Faccamp ${ }^{1}$ \\ Elizeu Belê - Faccamp ${ }^{2}$
}

\begin{abstract}
Resumo: Nas corporações modernas, os gerentes são os agentes responsáveis para traduzir ao nível operacional as diretrizes estratégicas da alta administração. Um dos seus papéis mais relevantes é criar um ambiente no qual as pessoas se sintam à vontade para contribuir com ideias, tomar iniciativas de melhorias e, assim, promover uma cultura orientada ao empreendedorismo, condição vital para as corporações se manterem competitivas e dinâmicas. Nessa linha, o presente estudo analisa a influência dos gerentes na percepção dos funcionários acerca do grau de orientação empreendedora da empresa. Realizado por meio de análise exploratória de dados obtidos de 142 mil funcionários de 552 empresas no Brasil em um estudo sobre clima organizacional em 2008, as empresas participantes foram segmentadas entre as mais orientadas ao empreendedorismo e as menos orientadas ao empreendedorismo, traçando os mesmos critérios de consulta no segmento de funcionários que ocupam posições de liderança. Ao comparar a percepção entre os dois grupos, foi possível identificar uma considerável correlação de percepção dentre as organizações mais orientadas ao empreendedorismo. Por outro lado, foi verificado que não houve o mesmo grau de correlação entre as percepções de gerentes e funcionários das organizações menos orientadas ao empreendedorismo. Também ficou evidente a diferença de perfil demográfico entre gerentes dos dois grupos de organizações, levando à conclusão de que a falta de uma orientação empreendedora percebida pelos funcionários tenha explicações nas atitudes e comportamentos das lideranças e sugere mudanças no perfil dos gerentes em favor de uma cultura empreendedora na organização.
\end{abstract}

Palavras-chave: Intraempreendedorismo; Gerente Empreendedor; Liderança Empreendedora; Empreendedorismo Corporativo; Orientação Empreendedora.

\section{THE IMPORTANCE OF MANAGERS IN ENTREPRENEURIAL ORIENTATION}

Abstract: In modern corporations, managers are the agents responsible for translating to the operational level the strategic directives of senior management. One of their most important roles is to create an environment in which people feel free to contribute with ideas, take initiatives for improvement and by so, promoting an enterprising oriented culture, a vital condition for corporations to remain competitive and dynamic. Along this line, this study analyzes the influence of managers in employee perception of the degree of enterprising orientation of the company. Conducted through exploratory analysis of data obtained from 142 thousand employees of 552 companies in Brazil in a study on organizational climate in 2008, participating companies were classified between the most enterprising orientation group and the less enterprising orientation group. The same classification criteria were traced in the segment of employees who occupy positions of leadership. When comparing the perception between the two groups, it was possible to identify a significant correlation of

\footnotetext{
${ }^{1}$ E.mail: prof.hashimoto@uol.com.br - Endereço: Rua Guatemala, 167, Jardim América, Campo Limpo Paulista - SP, CEP: 13231-230.

2 E.mail: e.bele@uol.com.br
}

DOI: 10.14211regepe32131. HASHIMOTO, M.; BELÊ, E. A importância dos gerentes na orientação empreendedora. Revista de Empreendedorismo e Gestão de Pequenas Empresas, v.3, n.2, p. 120-144, 2014. 
perception among most enterprising orientation organizations. On the other hand, It was verified that there has not been the same degree of correlation between the perceptions of managers and employees of organizations less geared to entrepreneurship. Also it became evident the difference in demographics between managers of the two groups of organizations, leading to the conclusion that the lack of enterprising orientation perceived by employees have explanations on the attitudes and behaviors of leaders and suggests changes in the profile of managers in favor of an enterprising culture in the organization.

Keywords: Intrapreneurship; Enterprising Manager; Enterprising Leadership; Corporate Entrepreneurship; Enterprising Orientation.

\section{Introdução}

A despeito do recente fenômeno de crescimento de estudos acadêmicos em torno do tema empreendedorismo corporativo no Brasil e no mundo, sobretudo evidenciado pelo destaque que este campo vem recebendo tanto em publicações acadêmicas de primeira linha como em eventos acadêmicos de empreendedorismo nos EUA, pouco ainda se conhece sobre o papel e a influência de determinados níveis hierárquicos no estabelecimento de fatores que caracterizam organizações orientadas ao empreendedorismo (OE).

Dentro da OE, o intraempreendedorismo é um fenômeno que se caracteriza por práticas autônomas e espontâneas iniciadas por funcionários de qualquer nível hierárquico e de qualquer função na organização, estando ligado diretamente ao clima organizacional. Um bom clima interno favorece a relação existente entre desempenho e capacidade inovadora dos funcionários. Isto já foi demonstrado em vários estudos, enaltecendo o tema como sendo de grande relevância em estudos sobre estratégia baseada em inovação.

Observações empíricas baseadas em depoimentos de funcionários entrevistados nestes estudos demonstram que as lideranças nas organizações desempenham papel relevante na formação desta cultura orientada ao comportamento empreendedor dos funcionários. A liderança também têm influência mais efetiva do que programas ou políticas de $\mathrm{RH}$ institucionalizadas e especialmente criadas para este fim (FRANCO; PACHECO; HASHIMOTO, 2014).

Tomando como base algumas destas evidências, o objetivo principal deste estudo é verificar a influência dos gerentes na formação da OE. Para atingir este objetivo, é fundamental estabelecermos como objetivo secundário a confirmação de

DOI: 10.14211regepe32131. HASHIMOTO, M.; BELÊ, E. A importância dos gerentes na orientação empreendedora. Revista de Empreendedorismo e Gestão de Pequenas

Empresas, v.3, n.2, p. 120-144, 2014. 
que se os gerentes de organizações voltadas à OE percebem suas empresas mais empreendedoras do que os gerentes das organizações menos orientadas ao empreendedorismo.

Outro objetivo secundário necessário como qualificação dos fundamentos deste estudo é a verificação de que se a formalidade do cargo ocupado pelos gerentes os torna mais propícios a adotar um comportamento empreendedor do que os demais colaboradores da organização. Este objetivo se justifica pelo fato de que a formalização da liderança pode exercer influência sobre a autoconfiança do funcionário e sua autonomia para adotar atitudes de natureza empreendedora.

\section{Liderança clássica}

Por décadas, as pessoas dependeram de fazendeiros, artesãos, comerciantes e proprietários para adquirir os produtos e serviços necessários para atender suas necessidades (KOTLER, 1982). A partir da Revolução Industrial, as oficinas onde os mestres e aprendizes realizavam o trabalho foram substituídas pela mecanização em escala, aumentando o grau de complexidade dos processos e suscitando a criação de uma nova realidade para as organizações (MAXIMIANO, 2008).

Fayol (1977) considerava a organização como sendo um sistema racional de regras e autoridade, dividida em seis funções principais: técnica, comercial, financeira, segurança, contabilidade e administração. Surge, então, a figura do gerente com a função de tomar decisões, estabelecer metas, definir diretrizes e atribuir responsabilidades aos integrantes da organização. Nessa perspectiva, o gerente atua como agente responsável por traduzir ao nível operacional as diretrizes estratégicas da alta administração e, consequentemente, comandar e organizar os recursos para produzir e entregar produtos e serviços aos clientes (BURNS, 1983).

Do mesmo modo que as organizações são fundamentais no ambiente externo ou no mercado, os gerentes também o são no ambiente interno. Para Drucker (1954), o trabalho do gerente pode ser comparado ao trabalho simultâneo do maestro e do intérprete, pois além de conduzir a orquestra, o gerente também desempenha o papel do intérprete. Para realizarem suas atividades, os gerentes 
desempenham diversos papéis ou funções diariamente, tornando-se objeto de diversos estudos a partir do século $X X$.

Tais estudos demonstraram que a participação dos gerentes como agente principal na complexa relação entre produtos/serviços e pessoas ampliou-se desde então, indo além das funções administrativas de planejar, organizar, comandar, coordenar e controlar. Para Mintzberg (1973), essas funções diluem-se e se combinam com o desempenho de diversos papéis, dentre os quais: os que abrangem as relações interpessoais, de relações públicas e intercâmbio de recursos e informações com seus pares; os papéis de interiorização e disseminação da informação para integrar e harmonizar os diversos atores da organização; e os papéis de tomada de decisão e resolução de problemas nas negociações e no controle de distúrbios e alocação estratégica de recursos.

Organizações com forte tendência à adoção da inovação como caminho estratégico, que promovem mudanças constantes, como lançar novos produtos, reduzir o quadro de funcionários e mudar a sede da empresa, requerem um tipo de liderança específico. Estes gerentes aprendem a adotar processos decisórios menos repetitivos e automáticos em favor de modelos decisórios não programados, que requerem capacidade de julgamento, intuição e criatividade, além da emoção (SIMON, 1997).

Essas habilidades permitem lidar com a complexidade de modo mais eficiente do que a tendência à simplificação excessiva que caracteriza as decisões tradicionais, fazendo com que as funções gerenciais dificilmente possam ser dissociadas do processo decisório. As organizações do século XXI exigem um novo perfil de liderança para lidar com essas circunstâncias mutáveis e inconstantes. É sobre este novo perfil de líder que será tratado a seguir.

\section{Empreendedorismo e intraempreendedorismo}

Os primeiros estudos sobre empreendedorismo encontram suas origens no trabalho de Richard Cantillon em 1755, que usou o termo para designar a receptividade ao risco de comprar algo por um preço e vendê-lo em regime de incerteza. Entretanto, a concepção de que o empreendedor é aquele que abre seu

DOI: 10.14211regepe32131. HASHIMOTO, M.; BELÊ, E. A importância dos gerentes na orientação empreendedora. Revista de Empreendedorismo e Gestão de Pequenas

Empresas, v.3, n.2, p. 120-144, 2014. 
próprio negócio foi convencionado a partir da definição de Jean Baptiste Say que, em 1803, refere-se ao empreendedor como aquele que transfere recursos econômicos de um setor de produtividade mais baixa para um setor de produtividade mais elevada e de maior rendimento (HASHIMOTO, 2013).

Os empreendedores apresentam algumas características comportamentais empreendedoras que, segundo McClelland (1972), são compostas por dez dimensões, podendo ser agrupadas em três conjuntos de acordo com seu significado. Assim, há o conjunto de realização, formado pela busca de oportunidades e iniciativa, persistência, comprometimento, exigência de qualidade e eficiência, e correr riscos calculados. O conjunto de planejamento é formado pelo estabelecimento de metas, busca de informação e planejamento e monitoramento sistemáticos. O terceiro e último conjunto é o de poder, formado pela persuasão e rede de contatos, independência e autoconfiança. Todas ou algumas dessas características comportamentais empreendedoras são percebidas em menor ou maior grau em todos os empreendedores individuais ou corporativos.

Tais características empreendedoras foram percebidas por Stevenson e Jarillo (1990) como relacionadas com o comportamento de funcionários de empresas que "perseguem oportunidades a despeito dos recursos que controlam". Convencionou-se denominá-los intraempreendedores ou funcionários que adotam um comportamento empreendedor, porém dentro das limitações impostas por uma organização já estabelecida.

Indo mais além, Kuratko e Hodgetts (2001) lecionam que intraempreendedores são pessoas que podem transformar ideias ou protótipos em realidades lucrativas sem precisar, necessariamente, criar novos produtos ou serviços. Não há diferenças perceptíveis entre empreendedores e intraempreendedores em relação ao comportamento e atitude. A aferição dos resultados da ação também parece seguir os mesmos critérios: inovação, conquista de imagem e mercado, melhorias, mudança, criação de valor e crescimento contínuo.

As diferenças, entretanto, se dão em outros elementos. Conhecer estas diferenças pode ser de grande valia para elencar quais dificuldades e oportunidades existem no ambiente das organizações, quando a pretensão for dotá-las de mais 
força empreendedora. Essa questão foi foco de pesquisas tanto de Bellu (1988) quanto de Buzenitz e Barney (1997). Ambos chegaram a conclusões similares que estão alinhadas com o conceito de que funcionários e intraempreendedores possuem visões distintas de mundo, motivações, atitudes e padrões de trabalho.

Hashimoto (2009) contribui com algumas explicações destas diferenças conforme apresentado no Quadro 1:

\begin{tabular}{|c|c|c|}
\hline CRITÉRIO & INTRAEMPREENDEDOR & FUNCIONÁRIO \\
\hline Motivação & $\begin{array}{l}\text { Em alto grau compensa algumas } \\
\text { deficiências } \\
\text { Sentimento de realização motiva } \\
\text { Dinheiro é consequência do trabalho }\end{array}$ & $\begin{array}{l}\text { É medido por suas deficiências } \\
\text { Dinheiro e poder motiva }\end{array}$ \\
\hline Contexto & $\begin{array}{l}\text { As iniciativas estão alinhadas com a missão } \\
\text { e objetivos da organização } \\
\text { Já conta com a infraestrutura existente ou } \\
\text { pelo menos, parte dela. }\end{array}$ & $\begin{array}{l}\text { Nem sempre conhece o negócio da } \\
\text { empresa } \\
\text { Só conta com a infraestrutura } \\
\text { existente }\end{array}$ \\
\hline Sonho & $\begin{array}{l}\text { Acreditam que podem realizar seus sonhos } \\
\text { e que eles estão alinhados com a visão } \\
\text { corporativa }\end{array}$ & $\begin{array}{l}\text { Seus sonhos pessoais estão } \\
\text { desconectados das atribuições } \\
\text { corporativas }\end{array}$ \\
\hline Risco & $\begin{array}{l}\text { Foca oportunidades } \\
\text { Corporação assume risco financeiro } \\
\text { Fracasso não é fatal } \\
\text { Extrapola funções e tarefas do cargo }\end{array}$ & $\begin{array}{l}\text { Gerencia recursos existentes } \\
\text { Evita riscos } \\
\text { Fracasso é fatal } \\
\text { Mantém-se aos limites do cargo e } \\
\text { função }\end{array}$ \\
\hline Inovação & $\begin{array}{l}\text { Impulsiona a inovação, maximizando a } \\
\text { aplicação de recursos para criar valor } \\
\text { Transforma ideias e protótipos em } \\
\text { realidade lucrativa }\end{array}$ & $\begin{array}{l}\text { Não estimula a inovação } \\
\text { Gerencia atividades mais focadas a } \\
\text { planejamento do que inovação }\end{array}$ \\
\hline $\begin{array}{l}\text { Atenção } \\
e \\
\text { Ação }\end{array}$ & $\begin{array}{l}\text { Tem iniciativa } \\
\text { Sabe usar a intuição } \\
\text { Conhece o negócio } \\
\text { É orientado para o futuro }\end{array}$ & $\begin{array}{l}\text { Não tem iniciativa } \\
\text { É racional e metódico } \\
\text { Não tolera incerteza e ambiguidade } \\
\text { É orientado para o passado }\end{array}$ \\
\hline Liderança & $\begin{array}{l}\text { É líder } \\
\text { Atrai fornecedores, clientes e talentos para } \\
\text { seu projeto } \\
\text { Comunica sua visão de forma clara e } \\
\text { realista. } \\
\text { Autogerencia-se compartilhadamente. }\end{array}$ & $\begin{array}{l}\text { É chefe } \\
\text { Só se relaciona com quem é } \\
\text { necessário } \\
\text { Diz às pessoas o que fazer } \\
\text { É conduzido por seus superiores }\end{array}$ \\
\hline Fracasso & $\begin{array}{l}\text { Teme, mas não o paralisa } \\
\text { Erros e fracasso fazem parte do } \\
\text { aprendizado } \\
\text { Acumula conhecimentos e experiências } \\
\text { diversificadas } \\
\text { Oculta projetos fracassados pela exposição } \\
\text { pública }\end{array}$ & $\begin{array}{l}\text { Teme e fica paralisado } \\
\text { Erros e fracassos podem marcar sua } \\
\text { carreira } \\
\text { Só se interessa pelo que tem } \\
\text { relevância } \\
\text { Receia que as falhas sejam } \\
\text { descobertas }\end{array}$ \\
\hline $\begin{array}{l}\text { Relaciona- } \\
\text { mentos }\end{array}$ & $\begin{array}{l}\text { Faz transações dentro da organização } \\
\text { Agrada a si mesmo, clientes e } \\
\text { patrocinadores. } \\
\text { Insere-se em redes intraempreendedoras } \\
\text { É um negociador interno }\end{array}$ & $\begin{array}{l}\text { Faz transações para cumprir metas } \\
\text { impostas } \\
\text { Agrada à chefia } \\
\text { Não amplia redes } \\
\text { Não é negociador }\end{array}$ \\
\hline
\end{tabular}

QUADRO 1 - Diferenças entre Funcionários e Intraempreendedores

Fonte: Adaptado de Hashimoto (2009).

DOI: 10.14211regepe32131. HASHIMOTO, M.; BELÊ, E. A importância dos gerentes na orientação empreendedora. Revista de Empreendedorismo e Gestão de Pequenas

Empresas, v.3, n.2, p. 120-144, 2014. 
A relevância dos intraempreendedores ganha corpo na medida em que a estratégia de diferenciação competitiva ganha espaço nas organizações. Isto é, a capacidade de gerar inovações, tanto em produtos e serviços quanto em processos, exige o desenvolvimento da capacidade de gerar e reter talentos com potencial para inovar, pois são as pessoas com esse perfil que possuem a capacidade de promover mudanças, além de implantar novos modelos e romper com padrões ultrapassados de práticas e gestão.

Orientação empreendedora

Tendo em mente as características elencadas anteriormente acerca do perfil empreendedor, seria possível dizer que em qualquer organização haveria um número tal de empreendedores que permitiria grandes saltos de competitividade. Porém, o ambiente interno das empresas é caracterizado pela abundância de profissionais com comportamentos que tendem mais ao de gerente clássico do que de empreendedores.

De acordo com Schumpeter (1982), que distingue aqueles que fazem "novas combinações" dos que "mantêm o fluxo":

\begin{abstract}
A atividade empreendedora não se restringe ao proprietário de empresas ou ao capitalista, mas a todos que realizam novas combinações de recursos do ambiente econômico, distinguindo-os dos dirigentes de empresas, que têm como objetivo operar um negócio estabelecido e a manter o fluxo circular da economia operante. (SCHUMPETER, 1982).
\end{abstract}

Um possível motivo para a escassez de intraempreendedores no ambiente corporativo é dado por Chisholm (1987). Segundo o autor, duas condições podem ser determinantes para esta escassez: ou os empreendedores potenciais pouco se vinculam às organizações de terceiros ou são naturalmente expelidos pelo ambiente burocrático existente nas grandes organizações.

Traduzir efetivamente 0 uso da capacidade inovadora dos intraempreendedores em resultados efetivos e significativos para a organização e seus principais atores acaba esbarrando em barreiras impostas por resistências 
internas a mudanças em práticas já institucionalizadas na organização (HASHIMOTO, 2009).

Nessa linha, cabe às organizações adotar medidas para identificar os intraempreendedores, criando condições para que as competências empreendedoras sejam desenvolvidas entre os funcionários e estabelecer mecanismos para reter os talentos mais empreendedores.

O conjunto de ações institucionais para este fim, a maior parte ligada às práticas de $\mathrm{RH}$, foi convencionado como Orientação Empreendedora (OE). A origem do conceito encontra-se no trabalho de Longenecker e Schoen em 1975 e continua sendo o mais aceito pela academia (HASHIMOTO, 2009). Os autores caracterizaram a OE através dos construtos inovação, tolerância a riscos e autonomia, devidamente respaldados por outros estudiosos e brevemente descritos no Quadro 2:

\begin{tabular}{|c|c|c|}
\hline CONSTRUTO & DESCRIÇÃO & AUTORES \\
\hline Inovação & $\begin{array}{l}\text { Busca de soluções criativas e não usuais } \\
\text { a problemas e necessidades, que pode vir na } \\
\text { forma de novas tecnologias ou processos. }\end{array}$ & $\begin{array}{l}\text { Schumpeter (1934) } \\
\text { Covin e Miles (1999) Pinchot } \\
\text { (1985), Longenecker e } \\
\text { Schoen (1975) }\end{array}$ \\
\hline $\begin{array}{l}\text { Tolerância } \\
\quad \text { a } \\
\text { Riscos }\end{array}$ & $\begin{array}{l}\text { Disposição de comprometer recursos } \\
\text { significativos para aproveitar oportunidades } \\
\text { com alguma chance de fracasso. O risco é } \\
\text { baseado em anomalias possíveis, } \\
\text { probabilidade de ocorrência destas } \\
\begin{array}{l}\text { anomalias e gravidade de } \\
\text { consequências. }\end{array}\end{array}$ & $\begin{array}{l}\text { Longenecker e Schoen } \\
\text { (1975) } \\
\text { Miller (1983) } \\
\text { Lumpkin e Dess (1996) } \\
\text { Mile e Arnold (1991) }\end{array}$ \\
\hline Autonomia & $\begin{array}{l}\text { Liberdade para agir sobre uma } \\
\text { oportunidade empreendedora, } \\
\text { perseverança, adaptabilidade e tolerância a } \\
\text { erros, decidindo sobre o uso de recursos, } \\
\text { escolhendo as estratégias e ação e obtendo } \\
\text { apoio e confiança de outros envolvidos. }\end{array}$ & $\begin{array}{l}\text { Covin e Miles (1999) } \\
\text { Morris, Allen, Schindehutte e } \\
\text { Avila (2006) } \\
\text { Longenecker e Schoen } \\
\text { (1975) }\end{array}$ \\
\hline
\end{tabular}

QUADRO 2 - Bases Teóricas dos Construtos da Orientação Empreendedora Fonte: Adaptado de Hashimoto (2009).

\section{Liderança empreendedora}

Estudos empíricos sugerem que uma boa parcela dos construtos que compõem a OE está relacionada com as práticas dos líderes organizacionais (SADLER-SMITH; EL-KOT; LEAT, 2003, TARABISHY et al., 2005).

DOI: 10.14211regepe32131. HASHIMOTO, M.; BELÊ, E. A importância dos gerentes na orientação empreendedora. Revista de Empreendedorismo e Gestão de Pequenas Empresas, v.3, n.2, p. 120-144, 2014. 
Estudos recentes ressaltam o surgimento de um novo tipo de liderança, mais alinhado com os desafios organizacionais recentes, a chamada "liderança empreendedora" (MCGRATH; MACMILLAN, 2000, TARABISHY et al., 2005).

Líderes empreendedores estimulam o comportamento empreendedor de seus liderados, tomando como base a capacidade que esses líderes têm em gerar soluções não convencionais para problemas existentes do dia a dia, incorrendo nos riscos inerentes à iniciativa autônoma de tentar algo diferente e criativo, em função das incertezas que podem levar ao fracasso, porém assumindo para si as responsabilidades e os resultados, sejam eles positivos ou negativos (HASHIMOTO, 2009).

O líder empreendedor tem uma visão crítica com relação às suas atitudes e ações perante cada membro da equipe, baseando a sua gestão na autoconfiança, valorização das pessoas, sinergia da equipe e um processo de comprometimento e cooperação mútua entre as pessoas (ROBBINS, 2002).

A influência dos líderes empreendedores afeta tanto a postura dos subordinados como a estratégia da organização (TARABISHY et al., 2005). De acordo com Timmons e Spinelli (2004) o líder empreendedor sabe que, para transformar a empresa e atingir seus objetivos, precisa não só estar em contato direto com os colaboradores, participando junto dos trabalhos desenvolvidos e proporcionando oportunidade para esses trabalhadores, como também deve desenvolver seu próprio perfil empreendedor.

Neste sentido, tanto Farrell (1993) como Filion (1999) entendem que os papéis do empreendedor (na definição de contextos) e o do gerente (na organização de recursos) são destacados, levando a especular se a geração de novos empreendedores dentro das organizações não seria também uma tarefa de empreendedores: a empresa desenvolve o empreendedor, que desenvolve a empresa e assim sucessivamente.

Altman e Zacharakis (2000) apontam que os modelos de desenvolvimento de empreendedores nas empresas estão tão impregnados da cultura dominante que é praticamente impossível transferi-los na íntegra para outras organizações. Desta forma, é essencial ressaltar a importância de líderes que também tenham características empreendedoras na criação de um ambiente que promova os 
intraempreendedores para estabelecer a inovação como forma de geração de estratégias competitivas.

Com base nestes conceitos, o estudo empírico buscou evidências que ajudassem a compreender o papel destes gerentes em organizações orientadas ao empreendedorismo.

\section{Procedimentos metodológicos}

Para atender ao objetivo de verificar a influência dos gerentes na formação da OE e se os gerentes de organizações orientadas ao empreendedorismo percebem suas empresas mais empreendedoras do que os das organizações menos orientadas ao empreendedorismo, e diante da carência de estudos sobre o tema no Brasil, foi adotado o método exploratório.

De acordo com Cervo, Bervian e Da Silva (2007), o método exploratório é normalmente o primeiro passo no processo de pesquisa empírica, pois busca mais informações sobre determinado assunto de estudo para aumentar a familiarização com o fenômeno.

Os dados foram obtidos por meio do Programa de Estudos em Gestão de Pessoas (PROGEP) da FIA (Fundação Instituto de Administração), que realiza anualmente o guia As Melhores Empresas para Você Trabalhar no Brasil, desde 2006. Esse guia é um dos mais completos sobre clima organizacional e traz informações sobre o clima levantadas em empresas no Brasil. A edição de 2008 contou com questões adicionais específicas sobre OE.

Os dados foram coletados no período de setembro de 2008 a março de 2009, com 142.913 funcionários de 552 empresas formais, sendo que 6,56\% dos respondentes (9.374) se declararam exercendo a função de gerentes ou superior. A unidade de análise foi o funcionário, escolhido de forma aleatória entre os cadastrados formalmente e informados pela empresa. Na amostra escolhida não há nenhuma restrição sobre localidade ou segmento de atuação e, em termos de porte, foram selecionadas apenas empresas com mais de 300 funcionários.

O questionário com 80 perguntas foi dividido em duas partes. Na primeira parte, as perguntas são compostas de variáveis de controle e independentes, de 
natureza fechada, para melhor tabulação dos resultados na abordagem do paradigma positivista: gênero, idade, tempo de casa, nível de instrução, número de filhos, cargo e salário. Na segunda parte do questionário, as variáveis independentes correspondem a 68\% das perguntas e as afirmações apresentadas para os respondentes atribuíram uma opção a um conjunto de alternativas segundo a escala Likert de atitude em 5 pontos (MARCONI; LAKATOS, 2008).

A orientação empreendedora, objeto de interesse deste estudo, foi identificada através da formulação de seis questões que refletem a percepção do empregado sobre os construtos da OE: inovação, receptividade a riscos e autonomia. O índice de OE é uma média simples obtida a partir dos valores mencionados no questionário do empregado para estas seis questões.

Para separar as empresas em mais e menos orientadas ao empreendedorismo, utilizou-se o índice de Nihans para classificá-las em empresas classe A e empresas classe C. O índice de Nihans é utilizado para separar um conjunto homogêneo de itens quantificados, sendo mais importantes (Classe A) aqueles maiores que o índice e menos importantes (Classe Não-A) aqueles inferiores ao índice. A aplicação do índice sobre a Classe Não-A propicia, analogamente, a identificação dos itens menos importantes (Classe C, aqueles menores que o índice) e dos itens de mediana importância (Classe B, aqueles maiores que o índice). Calcula-se o índice de Nihans por meio da fórmula:

$$
N=\Sigma\left(X^{2}\right) / \Sigma(X), \text { onde } \quad \begin{aligned}
& N=\text { Índice de Nihans } \\
& X=\text { Índice de OE }
\end{aligned}
$$

Para dar rigor às análises, verificou-se se o método do índice de Nihans efetivamente separou as empresas em grupos significativamente diferentes, ou seja, se há diferença estatisticamente significante entre o índice de OE das empresas Classe A e das empresas Classe C. Para tanto, foi aplicado o teste $z$, resumo amostral, comparando as médias, o tamanho da amostra e as variâncias do índice de OE das empresas Classe A e Classe C.

Casos em que os valores de uma variável podem responder questões relacionadas com os valores de outra foram tratados com técnicas de análise de 
correlação. Esta análise permite verificar se se tratam de variáveis interdependentes, ou seja, se quando uma variável muda a outra muda também, de maneira previsível, o que não quer dizer que exista uma associação entre elas, pois é possível que resultados significantes denunciem a existência de uma terceira ou mais variáveis que exerçam o mesmo grau de influência sobre as variáveis analisadas.

Os casos de variáveis contínuas linearmente correlacionadas foram tratados pela identificação do coeficiente de correlação de Pearson (r) (COOPER; SCHINDLER, 2001). Foi aplicado um teste estatístico que mostra a magnitude e o grau de relacionamento e a probabilidade de tal relacionamento ocorrer devido ao erro amostral (MARCONI; LAKATOS, 2008).

Tais relações foram apresentadas na forma de diagramas de dispersão, pois fornecem um meio visual que mostram não apenas a forma, mas também a direção que a relação demonstra. Em seguida, foi feita uma análise de regressão para determinar a equação linear que modela a relação entre as duas variáveis analisadas. Uma vez projetada a reta sobre o diagrama de dispersão, foi possível verificar o grau de dispersão em relação à reta, seu intercepto quando cruza o eixo $Y$ e o coeficiente de regressão que determina a inclinação da reta.

O coeficiente de correlação de Pearson ( $r$ ) consolidou os resultados das distâncias dos pontos do diagrama de dispersão em relação à reta do modelo. Quanto maiores às distâncias médias, maior o r, chegando ao máximo de 1,00 no caso de correlações perfeitas (ou seja, a distribuição dos pontos representa a própria reta) e ao mínimo de zero, quando não há nenhuma relação entre as duas variáveis. Para realizar as análises foi utilizado o software estatístico BioEstat 5.0.

\section{Resultados e análise}

A seguir estão demonstrados os resultados obtidos por meio dos procedimentos de coleta de dados. 


\section{Empresas classe A e classe C}

Para este estudo, das 552 empresas que participaram da pesquisa, após a filtragem e eliminação dos questionários inconsistentes, foram eliminadas 58 que ou não apresentaram respondentes gerentes ou o índice de OE estava zerado. Deste modo, 494 empresas foram consideradas para o cálculo do índice de Nihans.

O índice de Nihans calculado para empresas Classe A foi de 22,63. Logo uma amostra de 229 empresas com índice de OE maior do que 22,63 foi classificada como empresas Classe A. O índice de Nihans calculado na amostra após a remoção das empresas Classe $A$ foi de 21,18, isto é, as 123 empresas com índice de OE menor que 21,18 foram classificadas com empresas Classe C. A estatística descritiva calculada através do sofware BioEstat 5.0 está demonstrada na Tabela 1:

TABELA 1 - Estatística Descritiva do Índice de OE das Empresas

\begin{tabular}{l|c|c|c}
\hline Estatística descritiva & $\begin{array}{c}\text { Todas as } \\
\text { empresas }\end{array}$ & $\begin{array}{c}\text { Empresas } \\
\text { Classe A }\end{array}$ & $\begin{array}{c}\text { Empresas } \\
\text { Classe C }\end{array}$ \\
\hline Tamanho da Amostra & 494 & 229 & 123 \\
Mínimo & 16,881 & 22,634 & 16.881 \\
Máximo & 30,000 & 30,000 & 21,185 \\
Mediana & 22,525 & 23,790 & 20,320 \\
Média Aritmética & 22,481 & 24,049 & 20,167 \\
Variância & 3,366 & 1,299 & 0,654 \\
Desvio Padrão & 1,835 & 1,140 & 0,809 \\
İndice de Nihans & - & $>22,63$ & $<21,18$ \\
\hline Fonte: Elaborado pelos autores (2014)
\end{tabular}

Fonte: Elaborado pelos autores (2014).

Para verificar se entre as amostras classificadas como Classe A e Classe C há diferença significativa, utilizou-se o teste z: resumo amostral. De acordo com o teste, pode-se afirmar, ao nível de significância de 0,001, que há diferença significativa entre as duas amostras (Figura 1). 


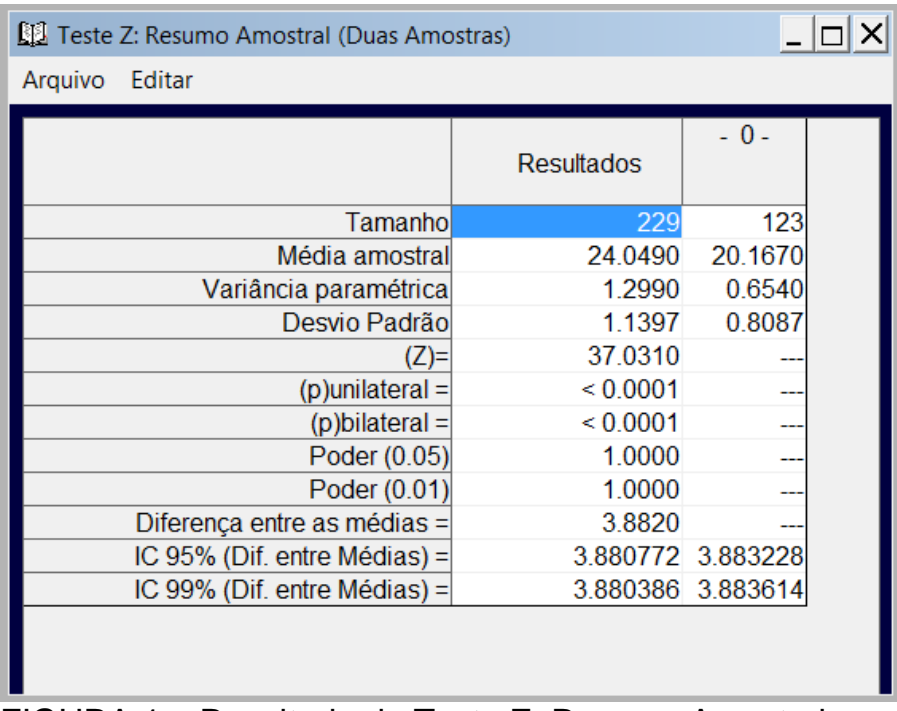

FIGURA 1 - Resultado do Teste Z: Resumo Amostral

Fonte: Elaborado pelos autores (2014).

\section{Gerentes classe A e classe C}

Definidas as empresas Classe A e Classe C, calculou-se o índice de OE percebido pelos respondentes que se declararam gerentes das empresas, isto é, a análise focalizou mais os aspectos táticos relacionados ao cargo do que os aspectos estratégicos e operacionais que forçariam a inclusão dos cargos de diretores e supervisores, respectivamente.

A tabela 2 apresenta o resultado das estatísticas descritivas realizadas após o cálculo do índice de OE das empresas percebido pelos gerentes. De acordo com a tabela 2, a média do índice de OE percebido pelos gerentes, tanto das empresas Classe $\mathrm{A}$ quanto das empresas Classe $\mathrm{C}$, que daqui para frente serão chamados de Gerentes Classe A e Gerentes Classe C, é maior do que a média das empresas, indicando que os gerentes tem participação significativa na OE das empresas.

TABELA 2 - Estatística Descritiva do Índice de OE dos Gerentes

\begin{tabular}{cccc}
\hline Estatística descritiva & Gerentes empresas Classe & Gerentes empresas Classe \\
\hline Tamanho da Amostra & $\mathrm{A}$ & $\mathrm{C}$ \\
Número de gerentes & 229 & 123 \\
Mínimo & 5123 & 1753 \\
Máximo & 20,800 & 15.000 \\
Mediana & 30,000 & 29,000 \\
Média Aritmética & 25,657 & 23,143 \\
Variância & 25,822 & 23,143 \\
Desvio Padrão & 3,400 & 6,009 \\
\hline
\end{tabular}

Fonte: Elaborado pelos autores (2014).

DOI: 10.14211regepe32131. HASHIMOTO, M.; BELÊ, E. A importância dos gerentes na orientação empreendedora. Revista de Empreendedorismo e Gestão de Pequenas Empresas, v.3, n.2, p. 120-144, 2014. 
Para verificar se entre as amostras dos gerentes Classe A e C há diferença significativa utilizou-se o teste $\mathrm{z}$ : resumo amostral. De acordo com o teste, pode-se afirmar, ao nível de significância de 0,001, que há diferença significativa entre as duas amostras (Figura 2), confirmando que Gerentes Classe A percebem suas empresas mais orientadas ao empreendedorismo do que Gerentes Classe C.

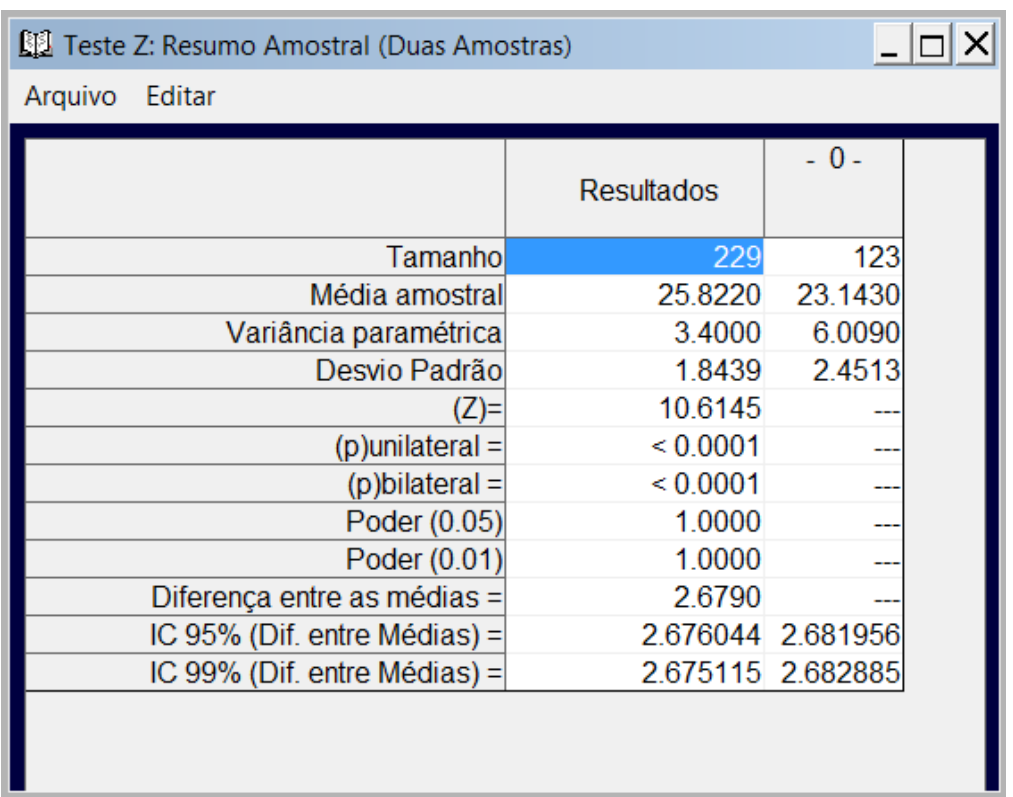

FIGURA 2 - Resultado do Teste Z: Resumo Amostral

Fonte: Elaborado pelos autores (2014).

Sabendo-se que os Gerentes Classe A percebem suas empresas mais orientadas ao empreendedorismo do que os Gerentes Classe C, verificou-se se o índice de $\mathrm{OE}$ percebidos pelos gerentes aderem ao índice de $\mathrm{OE}$ de suas respectivas empresas utilizando o teste de correlação linear de Pearson. O índice de OE percebido pelos Gerentes Classe A foram correlacionados com o das empresas Classe A (Figura 3A). De acordo com o teste, pode-se afirmar, ao nível de significância de 0,001, que o índice de OE percebido pelos Gerentes Classe A adere ao índice de OE das empresas Classe A.

Entretanto, o índice de OE percebido pelos Gerentes Classe C, quando correlacionados com o das empresas Classe C (Figura 3B), indicaram que se pode afirmar, ao nível de significância de 0,001, que o índice de OE percebido pelos mesmos não adere ao índice de OE das empresas Classe C. Isto é, os Gerentes 
Classe C apresentam uma percepção do índice de OE bem acima do índice de OE das empresas Classe C.

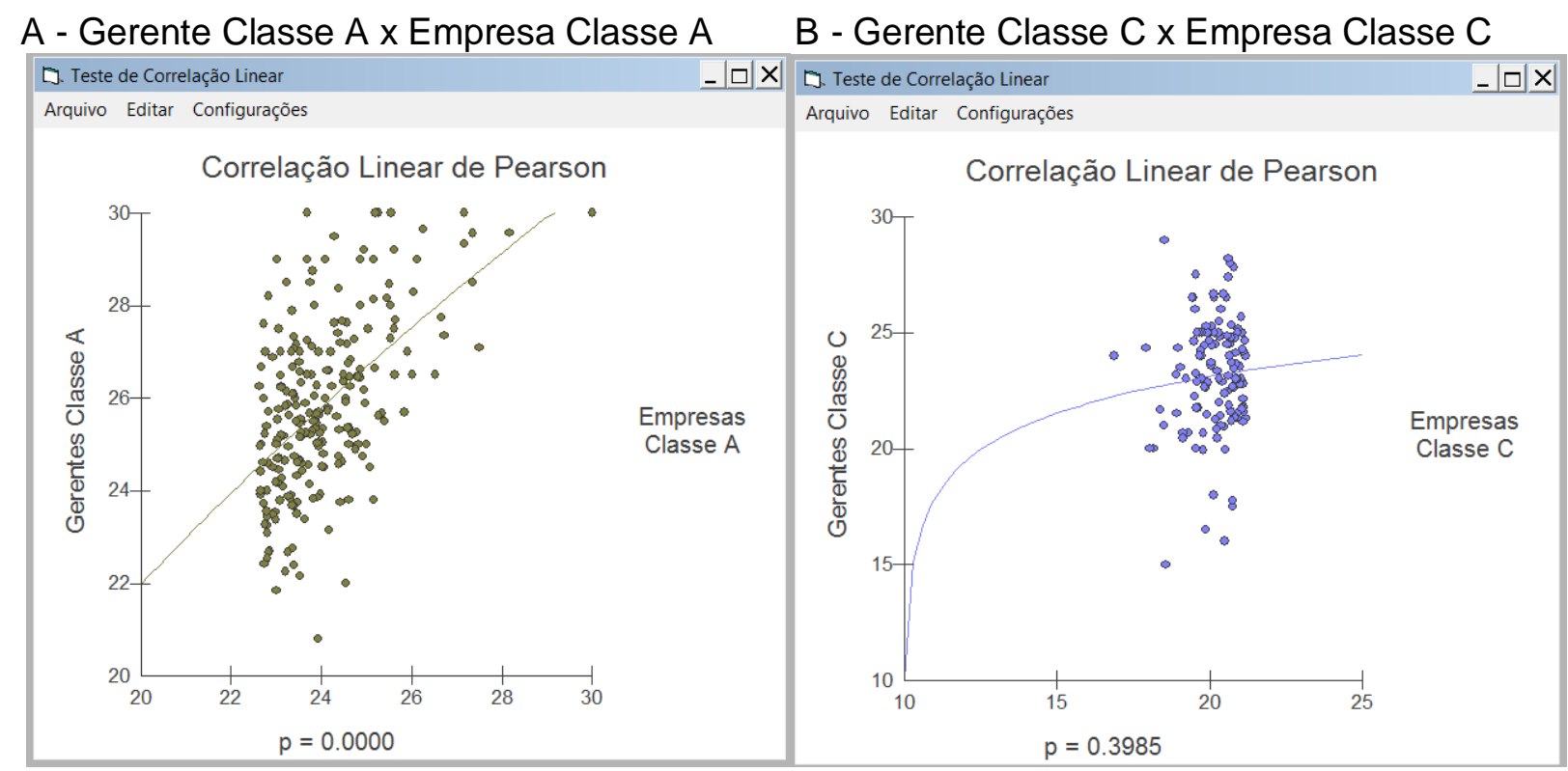

FIGURA 3 - Resultado do Teste de Correlação Linear de Pearson

Fonte: Elaborado pelos autores (2014).

\section{Perfil dos gerentes classe A e classe C}

A análise demográfica dos gerentes apresentou os seguintes perfis:

Por gênero

As empresas Classe C apresentam uma participação maior em $11,2 \%$ de mulheres gerentes do que as empresas Classe A (Gráfico 1). Uma análise somente das Gerentes Classe A indicou que o índice de OE percebido por elas é 21,56, enquanto o dos Gerentes Classe A é 22,62, podendo indicar que as mulheres possuem uma postura mais exigente em relação às políticas e diretrizes da empresa.

DOI: 10.14211regepe32131. HASHIMOTO, M.; BELÊ, E. A importância dos gerentes na orientação empreendedora. Revista de Empreendedorismo e Gestão de Pequenas Empresas, v.3, n.2, p. 120-144, 2014. 


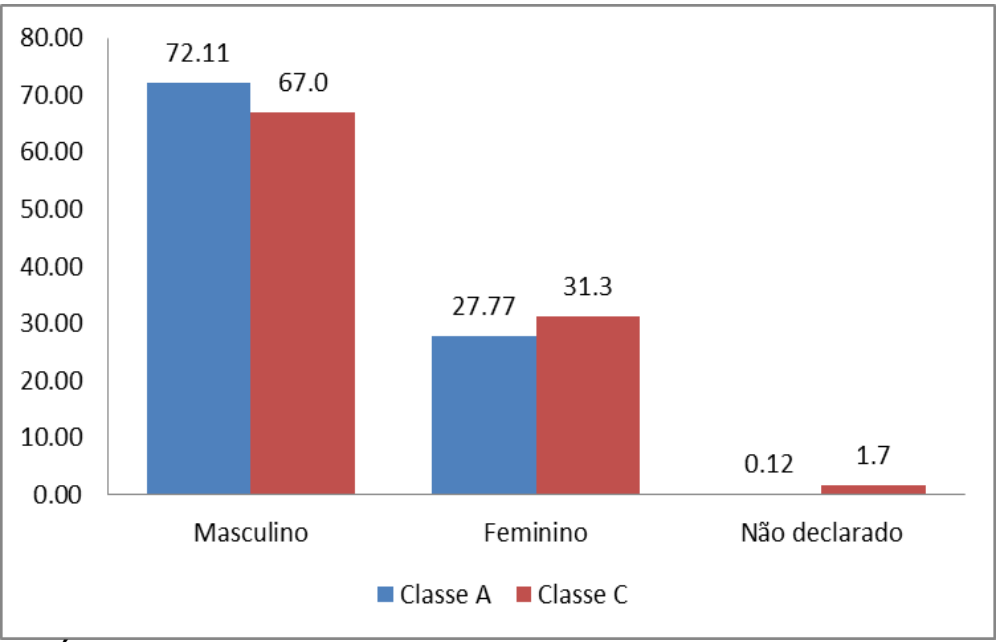

GRÁFICO 1 - Distribuição dos Gerentes por Gênero (em \%) Fonte: Elaborado pelos autores (2014).

Por faixa etária

A distribuição por faixa etária apresenta algumas características peculiares. As empresas Classe A possuem $37,8 \%$ de gerentes na faixa de 25 a 35 anos de idade contra $30,6 \%$ das empresas Classe C. Já as empresas Classe $C$ possuem $23,4 \%$ dos gerentes na faixa de 46 a 55 anos de idade, enquanto as empresas Classe A tem somente 18\% (Gráfico 2).

Isto talvez explique porque as empresas Classe A são mais orientadas ao empreendedorismo do que as da Classe $\mathrm{C}$, pois fazendo uma correlação com os estágios da empresa, os gerentes na faixa de 25 a 35 anos de idade estão na fase mais empreendedora da carreira, os gerentes de 36 a 45 anos estão no estágio de transição e os na faixa de 46 a 55 anos de idade estão na fase de estabilidade na carreira.

Gerentes no estágio empreendedor estão mais dispostos a correr riscos, promovem mais mudanças, procuram inovar com mais frequência, são mais competitivos, aprendem mais rápido, são mais ambiciosos, mais dinâmicos e ativos do que gerentes no estágio de estabilidade. 


\section{A Revista da ANEGEPE

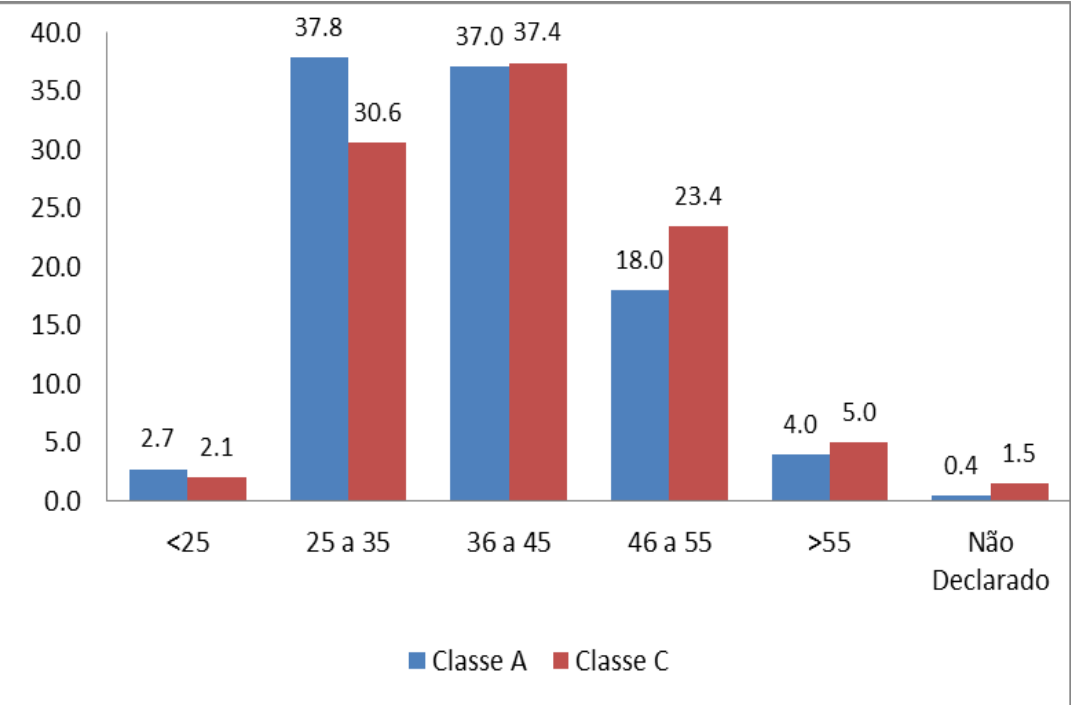

GRÁFICO 2 - Distribuição dos Gerentes por Faixa Etária (em \%)

Fonte: Elaborado pelos autores (2014).

Por nível educacional

A análise do perfil dos gerentes considerando a formação indica que nas empresas Classe A, a maioria dos gerentes (52\%) são pós-graduados, enquanto que nas empresas Classe $\mathrm{C}$ há mais gerentes com Ensino Médio, Superior incompleto e Graduado do que nas empresas Classe A (Gráfico 3). Esta evidência leva à suposição de que organizações orientadas ao empreendedorismo requerem líderes mais qualificados, com melhor preparação para promover e conduzir iniciativas de natureza empreendedora e inovadora.

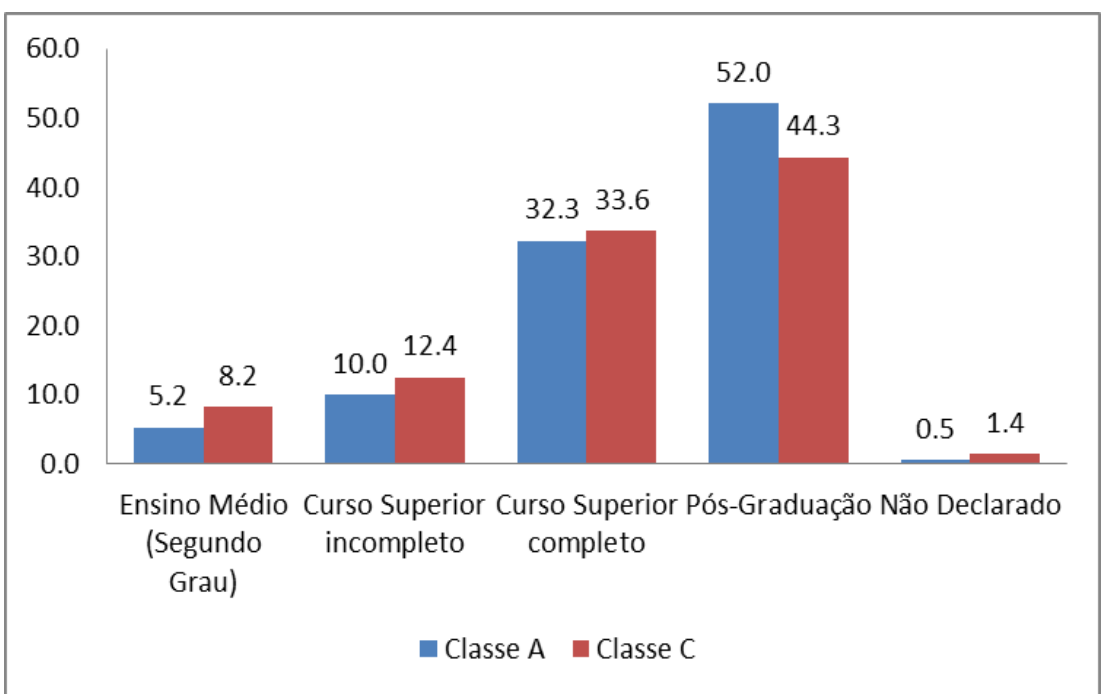

GRÁFICO 3 - Distribuição dos Gerentes por Nível Educacional (em \%) Fonte: Elaborado pelos autores (2014).

DOI: 10.14211regepe32131. HASHIMOTO, M.; BELÊ, E. A importância dos gerentes na orientação empreendedora. Revista de Empreendedorismo e Gestão de Pequenas Empresas, v.3, n.2, p. 120-144, 2014. 
Por tempo de casa

As empresas Classe A apresentam uma distribuição significativamente maior de gerentes com até 10 anos de casa, enquanto que as empresas Classe C invertem essa característica, apresentando uma distribuição significativamente maior de gerentes com mais de 16 anos de casa (Gráfico 4). Isto corrobora com a análise realizada no item 5.3.2, onde, com o passar do tempo, os gerentes de um modo geral tendem a agir com menor disposição para mudanças ou para promover as inovações.

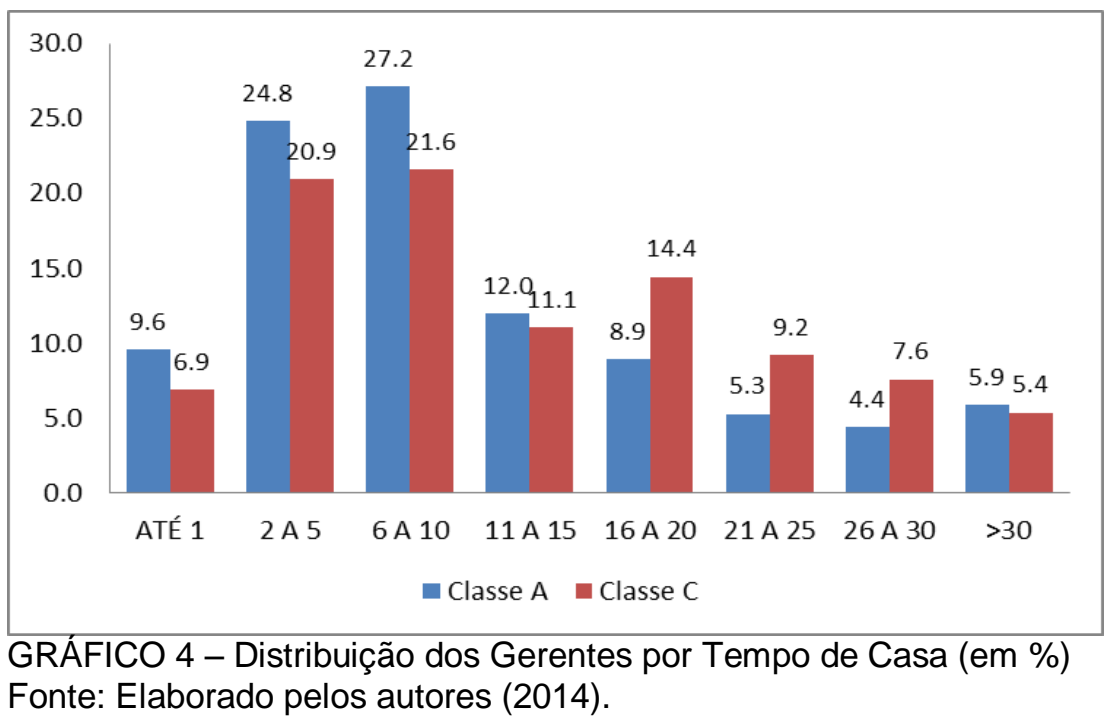

Como existe uma correlação entre tempo de casa e posição na hierarquia, pode-se também inferir que, com mais tempo de casa, embora o gerente tenha mais poder, corre também mais riscos ao promover inovações. Aqueles com menos tempo de casa, por outro lado, além de estarem mais predispostos a realizar mudanças, estão menos influenciados pela institucionalização das práticas, podendo ter mais ideias e perceber mais oportunidades do que aqueles com mais tempo de casa.

\section{Considerações finais}

O presente estudo demonstrou que a percepção dos gerentes das empresas Classe A está alinhada significativamente com a percepção dos demais DOI: 10.14211regepe32131. HASHIMOTO, M.; BELÊ, E. A importância dos gerentes na orientação empreendedora. Revista de Empreendedorismo e Gestão de Pequenas 
colaboradores da empresa. Isto é, as estratégias da organização voltadas para a orientação empreendedora estão sendo traduzidas efetivamente por toda a organização.

A percepção de um grau de OE satisfatório pelos colaboradores indica que o clima organizacional está fortemente influenciado pela OE nas estratégias, políticas e diretrizes da empresa. Sendo que as políticas e diretrizes estão atingindo o objetivo de criar uma cultura organizacional que possibilita a criação de um ambiente propício para o surgimento de intraempreendedores, começando pela percepção de que o empreendedorismo é valorizado e incentivado.

Já os colaboradores das empresas Classe C não reconhecem nas políticas e diretrizes da empresa possibilidades de ações que desenvolvam a $O E$, contrariando a percepção dos seus gerentes que percebem um grau de OE acima da média na empresa.

Assim, o resultado da pesquisa leva a crer que os gerentes das empresas Classe C não conseguem traduzir as estratégias da empresa em políticas e diretrizes que estabeleçam condições de desenvolvimento da OE dentro da organização. Pode-se especular que os gerentes das empresas Classe C acreditam que fazem o necessário para traduzir efetivamente essas estratégias a todos os níveis da organização, daí creditarem nota alta ao grau de OE da empresa, mas falta-Ihes um feedback adequado para essa avaliação. Feedback este que parece não faltar para os gerentes das empresas Classe A, que tem os mesmos discursos e pontos de vista dos demais colaboradores, demonstrando uma integração forte e harmônica quanto à OE da empresa.

A análise do perfil demográfico fornece alguns indicadores que podem justificar essa dissonância entre as percepções dos gerentes sobre suas respectivas empresas. Quando se põe o foco nos gerentes das empresas Classe A, verifica-se um perfil predominantemente masculino (72,11\%), jovem entre 25 e 35 anos de idade, com Pós-Graduação (52\%) e tempo de casa até 10 anos. Em contrapartida, os gerentes das empresas Classe C apresentam um perfil também predominantemente masculino (67,00\%), mas com uma participação feminina $11,2 \%$ maior do que nas empresas Classe A, com menor frequência de Pós-Graduados 
(44,3\%) do que nas empresas Classe A, idade média entre 36 e 55 anos e tempo de casa acima de 16 anos.

Primeiramente, a presença significativa de homens nos dois casos reflete uma cultura empresarial que ainda dificulta o acesso das mulheres aos cargos de gerência. Por outro lado, a maior presença feminina nas empresas Classe C contrabalanceou a visão otimista dos gerentes, funcionando como redutora e indicando uma forte correlação da percepção delas com a dos demais colaboradores da empresa. Deste modo, pode-se afirmar que a distorção da percepção dos gerentes em relação à percepção dos demais colaboradores só não foi mais acentuada devido à presença feminina, indicando uma posição critica positiva e construtiva das mulheres.

Já a alta presença de jovens nos cargos gerenciais nas empresas Classe $A$ pode indicar que essas empresas promovem uma renovação no seu quadro gerencial com maior frequência do que as empresas Classe $\mathrm{C}$, fato confirmado com a diferença de tempo de casa entre as duas empresas, fator fundamental para a criação de uma cultura orientada ao empreendedorismo.

Uma maior participação de gerentes com Pós-Graduação nas empresas Classe A demonstra a influência positiva do conhecimento e a formação de uma cultura orientada ao empreendedorismo, facilitando e embasando a tomada de decisão para promover inovações e mudanças a partir da iniciativa de funcionários, pois possibilita o equilíbrio dinâmico entre autonomia, assumir riscos calculados e inovar.

Após o exposto acima, conclui-se que o papel dos gerentes impacta no grau de OE da organização de forma determinante, tanto na divulgação quanto na implantação das estratégias que nortearão o comportamento e comprometimento dos colaboradores com a inovação. A sintonia dos gerentes com a OE da empresa através do desenvolvimento de competências voltadas à liderança empreendedora, ao aprimoramento do conhecimento da cultura e do comportamento organizacional da empresa, ao conhecimento do setor onde atua a empresa, à gestão de projetos, à elaboração de planos de negócio e ao programa de recrutamento interno, é fundamental para que eles exerçam efetivamente o papel de disseminadores do empreendedorismo dentro das organizações.

DOI: 10.14211regepe32131. HASHIMOTO, M.; BELÊ, E. A importância dos gerentes na orientação empreendedora. Revista de Empreendedorismo e Gestão de Pequenas

Empresas, v.3, n.2, p. 120-144, 2014. 
Nessa esteira, o perfil demográfico dos Gerentes Classe C apresenta características que podem induzir a uma avaliação enviesada e tendenciosa, pois apresenta uma maior participação de mulheres, profissionais mais velhos entre 46 e 55 anos de idade, a maioria com grau de instrução entre Ensino Médio, Graduação e com tempo de casa superior a 16 anos.

Para uma conclusão mais objetiva são necessárias novas pesquisas que busquem explicações sobre o papel das mulheres nos cargos gerenciais, a influência da idade no comportamento empreendedor, a efetividade ou existência do plano de carreira e quais fatores reducionistas aparecem com o aumento do tempo de casa.

Embora esta pesquisa tenha contribuído com estudos sobre as influências das lideranças na $\mathrm{OE}$, nas práticas de $\mathrm{RH}$, existem ainda excelentes oportunidades para complementar este estudo por meio das inúmeras dúvidas que aqui foram suscitadas, a saber:

1. Quais são os fatores específicos que levam as empresas Classe C a um baixo grau de OE?

2. A baixa correlação na percepção de OE entre Gerentes Classe C e funcionários de empresas Classe $\mathrm{C}$ se deve à falta de autopercepção dos gerentes sobre o real grau de $\mathrm{OE}$, às suas limitações em promover a OE ou à falta de percepção dos funcionários das ações realizadas pelos gerentes para promover a OE?

3. Apenas uma mudança no perfil demográfico dos gerentes das empresas Classe $\mathrm{C}$ é suficiente para que a OE ganhe espaço nas empresas?

4. Quais são as demais influências que caracterizam a menor OE em empresas Classe C?

A pesquisa desses questionamentos podem indicar caminhos reais para que a OE aconteça cada vez mais nas empresas, de forma a estimular a busca pela competitividade por meio do empreendedorismo corporativo, identificando, desenvolvendo e retendo talentos inovadores em todos os níveis da organização. 
Referências:

ALTMAN, J. W.; ZACHARAKIS, A. An integrative model for corporate venturing. frontiers of entrepreneurship research, Weslley, MA: Babson College, 2000.

BELLU, R. R. Entrepreneurs and managers: are they different? Frontiers of entrepreneurship research, Wellesley, MA: Babson College, 1988.

BURNS, E. M. História da Civilização Ocidental. Porto Alegre: Globo, 1983.

BUZENITZ, L. W.; BARNEY, J. B. Differences between entrepreneurs and managers in large organizations: biases and heuristics in strategic decision-making. Journal of Business Venturing, v. 12, n. 1, p. 9-30, jan. 1997.

CERVO, A. L.; BERVIAN, P. A.; DA SILVA, R. Metodologia Científica. 6ª . ed. São Paulo: Pearson Prentice Hall, 2007.

CHANDLER, A. Jr. The Visible Hand: The American Revolution in American Business. Cambridge: Harvard University Press, 1977.

CHISHOLM, T. A. Intrapreneurship and bureaucracy S.A.M. Advanced Management Journal, v. 52, n. 3, p. 36-40, jun. 1987.

COOPER, D. R.; SCHINDLER P. S. Métodos de Pesquisa em Administração. 7. ed. Porto Alegre: Bookman, 2001.

DRUCKER, P. F. The Practice of Management. New York: Harper \& Row, 1954.

FARREL, L. C. Entrepreneurship: fundamentos das organizações empreendedoras. São Paulo: Atlas, 1993.

FAYOL, H. Administração Industrial e Geral. São Paulo: Atlas, 1977.

FILION, L. J. O Empreendedorismo como tema de estudos superiores. In: Instituto Euvaldo Lodi (Org): Empreendedorismo, Ciência, Técnica e Arte. Brasília: CNI Instituto Euvaldo Lodi, 1999.

FRANCO, M. S.; PACHECO, S.; HASHIMOTO, M. Liderança Empreendedora e Práticas de $\mathrm{RH}$ : Um Estudo sobre a Eficácia na Promoção do Empreendedorismo Corporativo. Anais... Goiânia: VIII Egepe, 2014.

HASHIMOTO, M. Espírito Empreendedor nas Organizações: Aumentando a Competitividade através do Intraempreendedorismo. 3. ed. São Paulo: Saraiva, 2013.

DOI: 10.14211regepe32131. HASHIMOTO, M.; BELÊ, E. A importância dos gerentes na orientação empreendedora. Revista de Empreendedorismo e Gestão de Pequenas Empresas, v.3, n.2, p. 120-144, 2014. 
M. Organizações Intra-Empreendedoras: Construindo a Ponte entre Clima Interno e Desempenho Superior. 2009, 363 f. Tese (Doutorado em Administração de empresas) - Fundação Getúlio Vargas, São Paulo, 2009.

HASHIMOTO, M.; DE AVÓ, M. R.; SILVA, L. Y. The relevance of intrapreneurship in Small and Medium Size Business. In: United States Association of Small Business and Entrepreneurship Annual Conference Proceedings. San Antonio, TX, USA, 2008. Annais... San Antonio: 2008.

JONES, G. R.; BUTLER, J. E. Managing internal corporate entrepreneurship: an agency theory perspective. Journal of Management, v. 18, n. 4, p. 733-749, dez. 1992.

KOTLER, J. P. The General Managers. New York: Free Press, 1982.

KURATKO, D. F.; HODGETTS, R. M. Entrepreneurship: a contemporary approach. Orlando: Harcourt College Publishers, 2001.

MALHOTRA, N. K. Pesquisa de Marketing: Uma Orientação Aplicada. 4. ed. Porto Alegre: Bookman, 2006.

MARCONI, M. A.; LAKATOS, E. M. Técnica de Pesquisa: Planejamento e Execução de Pesquisas, Amostragens e Técnicas de Pesquisa, Elaboração, Análise e Interpretação de Dados. 7. ed. São Paulo: Atlas, 2008.

MAXIMIANO, A. C. A. Teoria Geral da Administração: da revolução urbana à revolução digital. 6 ed. São Paulo: Atlas, 2008.

McCLELLAND, D. C. Entrepreneurship and Achievement Motivation: Approaches to the Science of Socio-Economic Development. In: Lengyel, P. Paris: UNESCO, 1971.

D. A sociedade competitiva: realização e progresso social. Rio de Janeiro: Expressão e Cultura, 1972.

MCGRATH, R. G.; MACMILLAN, I. C. Assessing technology projects using real options reasoning. Research Technology Management, v. 43, n. 4, p. 35-50, jul. 2000.

MINTZBERG, H. The Nature of Managerial Work. New York: Harper \& Row, 1973.

$\mathrm{H}$. The Manager's Job: Folclore and Fact. Harvard Business Review, Boston, v. 54, n.4, p. 49-61, jul./ago. 1975.

ROBBINS, S. P. Comportamento Organizacional. São Paulo: Pearson, Prentice Hall, 2002.

DOI: 10.14211regepe32131. HASHIMOTO, M.; BELÊ, E. A importância dos gerentes na orientação empreendedora. Revista de Empreendedorismo e Gestão de Pequenas Empresas, v.3, n.2, p. 120-144, 2014. 
SADLER-SMITH, E.; EL-KOT, G.; LEAT, M. Differentiating work autonomy facets in a non-Western context. Journal of Organizational Behavior, v. 24, n. 6, p. 709-731, ago. 2003.

SCHUMPETER, J. A. Teoria do desenvolvimento econômico. São Paulo: Abril Cultural, 1982.

SIMON, H. A. Administrative Behavior: study of decision-making processes in administrative organization. New York: Macmillan, 1997.

H. A. Theories of decision making in economics and behavioral science. The American Economic Review, v. 49, p. 253-283, jun. 1959.

STEVENSON, H. H.; JARILLO, J. C. A paradigm of entrepreneurship: Entrepreneurial management. Strategic Management Journal, EUA, v. 11, edição especial, p.17-27, 1990.

TARABISHY, A.; SOLOMON, G.; FERNALD, L. W. Jr.; SASHKIN, M. The Entrepreneurial Leader's Impact on the Organization's Performance in Dynamic Markets. The Journal of Private Equity, v. 8, n. 4, p. 20-29, 2005.

TIMMONS, J.; SPINELLI, S. New Venture creation: Entrepreneurship for the 21st century. New York: Mc Graw-Hill/Irwin, 2004.

Artigo recebido em: 30/04/2014. Artigo aprovado em: 14/08/2014

DOI: 10.14211regepe32131. HASHIMOTO, M.; BELÊ, E. A importância dos gerentes na orientação empreendedora. Revista de Empreendedorismo e Gestão de Pequenas 